\title{
Filosofia e Literatura em Luciano de Samósata: o proêmio Das Narrativas Verdadeiras
}

\author{
Philosophy and Literature in Lucian of Samósata: the proem of A True Story
}

FABIO ANTONIO DA SILVA ${ }^{1}$

\begin{abstract}
Resumo: No presente artigo se propõe uma reflexão sobre a relação filosofia e literatura a partir dos parágrafos iniciais do livro Das Narrativas Verdadeiras ( $A \lambda \eta \theta \tilde{\eta} \delta i \eta \gamma \eta \dot{\eta} \mu \tau \tau \alpha)$ do escritor sírio helenizado Luciano de Samósata, que viveu no segundo século depois de Cristo como um cidadão do Império Romano. Obra que figura como exemplo paradigmático do que se veio chamar tradição luciânica, nela, por meio da alusão, o humor de Luciano nos leva até às reflexões mais refinadas da crítica dos costumes às elucubrações científicas; mas é ao desvelar o caráter ficcional da sua narrativa que nos oferece, ainda hoje, subsídio para teorizarmos sobre essa fronteira [tão contestável] entre o que é literatura e o que é filosofia.
\end{abstract}

Palavras-chave: Luciano de Samósata. Literatura. Filosofia.

Abstract: The present article is a reflection on the relation of philosophy and literature to the initial paragraphs of the book A True Story $(A \lambda \eta \theta \tilde{\eta} \delta i \eta \gamma \eta \dot{\eta} \mu \alpha \tau)$ by the Hellenized Syrian writer Lucian of Samosata, lived in the second century after Christ as a citizen of the Roman Empire. A work that appears as a paradigmatic example of what came to be called Lucianic tradition, in it, by means of the allusion, Luciano's humor takes us to the most refined reflections of the critic of customs to scientific explanations; but it is by revealing the fictional character of his narrative that he offers us, even today, a subsidy for theorizing about this [so contestable] frontier between what is literature and what is philosophy.

Keywords: Lucian of Samosata. Literature. Philosophy.

\section{Introdução}

Luciano de Samósata ( $\cong 125-181)$ é tido como o criador de uma tradição de textos com narrativas de viagens fantásticas que surgiram desde suas Das Narrativas Verdadeiras $^{2}$ (alguns diriam que se trata do fundador da ficção científica). Para além da sua importância literária esse texto pode ser avaliado do ponto de vista filosófico, em especial na leitura atenta do proêmio ${ }^{3}$ do texto que nos orienta na leitura de suas Narrativas. O autor sírio helenizado oriundo da capital do antigo reino de Comagena, então incorporada ao Império Romano, viveu durante o reinado de

\footnotetext{
${ }^{1}$ Bacharel em Filosofia pela Universidade Estadual do Oeste do Paraná (2008) e mestre em Filosofia pela Universidade Federal do Paraná (2013). Atualmente é doutorando em Filosofia também pela Universidade Federal do Paraná, pesquisador bolsista pela CAPES. E-mail: fabioantonio@ufpr.br

2 "Nesse sentido, já o título do texto parece anunciar do que se trata o seu conteúdo. O título $A \lambda \eta \theta \tilde{\eta}$ $\delta ı \eta \gamma \eta ́ \mu \alpha \tau \alpha$ é comumente traduzido como Histórias Verdadeiras. A decisão de traduzi-la por Das Narrativas Verdadeiras justifica-se pelo fato de a primeira opção apresentar uma simplificação do seu sentido" (SANO, Lucia, 2008).

3 Trecho do texto que o tradutor português Custódio Magueijo chama de preâmbulo (SAMÓSATA, Luciano de, Obras completas, Coimbra, 2012).
} 
Marco Aurélio (o filósofo estoico), tendo passado boa parte de sua vida fora de sua cidade natal ${ }^{4}$, acabou por morrer no Egito, na cidade de Alexandria. Muitas vezes classificado como um filósofo da Segunda Sofística por sua posição histórica (como se verá uma rotulação questionável) e ficou famoso por renovar os diálogos filosóficos acrescentando um caráter satírico aos mesmos: essa característica cômica e ao mesmo tempo crítica é fonte de reflexões filosóficas como se poderá ver na investigação do proêmio Das Narrativas Verdadeiras. A relação que o autor estabelece aí entre filosofia e literatura é, ainda hoje, fonte de uma rica reflexão que nos faz pensar o papel da imaginação no trabalho intelectual; bem como a fronteira entre verdade e ficção.

\section{Confesso que minto}

O proêmio a que nos referimos são os quatro parágrafos que abrem o texto de Luciano e preparam-nos para encarar as páginas vindouras. O primeiro parágrafo anuncia que o tipo de narrativa que iremos conhecer não se trata da leitura "prolongada” nem "das mais sérias", porém, já aí anuncia uma posição filosófica de Luciano: por meio de uma analogia entre os atletas e aqueles que se dedicam às letras, afirma o autor que, se para os primeiros o relaxamento é uma das partes principais de sua disciplina de treino para que alcancem a boa forma física, para os últimos convém relaxar o intelecto e deixá-lo mais arguto, mais forte para o esforço futuro; ou seja, há em suas narrativas algo de relaxamento do intelecto o qual é parte inalienável da prática das leituras sérias como as de filosofia.

Desse modo Luciano afirma uma utilidade prática para a leitura de suas narrativas, mas não para por aí: mesmo ali, nas suas narrativas que oferecem, sobretudo, prazer e graça por sua "proposta insólita"; há uma visão refinada (conforme sustenta no segundo parágrafo) quando - com suas alusões cômicas oferece uma crítica a historiadores e filósofos de então e do passado, e quando apresenta "mentiras convincentes e verossímeis".

Mentiras estas em que, como vemos no terceiro parágrafo, alguns "antigos poetas, historiadores e filósofos" incorreram sem tê-lo confessado: como prova Luciano cita o caso do historiador persa Ctésias de Cnido que escreveu sobre a Índia sem nunca tê-la visto ou dela colhido relatos, bem como Iâmbulo que mencionava de forma fantasiosa a viagem de uma frota de fenícios que teria saído da costa da África perto de Dakar, e navegado pelo "grande mar" (Oceano Atlântico); além de falar de modo geral de "muitos outros" que criaram feras e tipos inéditos de vida em seus relatos, para Luciano todos estes autores teriam seu guia em Homero com seu Odisseu "mestre nesse tipo de bufonaria".

\footnotetext{
4 “Da Âsia Menor passa para a Grécia, e daí para a Itália, mas é sobretudo na Gália que obtém glória e fortuna”(Ibid.p.8)
} 
No quarto e último parágrafo deste proêmio tendo, por assim dizer, desmascarado "antigos poetas, historiadores e filósofos", Luciano de Samósata, sem ter vivido nada digno de menção para relatar, e tomado "pelo desejo da vanglória", que sua ironia não poupa, resolve se juntar ao grupo dos mentirosos, uma vez que o relato que lemos na sequência (de sua navegação até a lua 5 , o sol e outros planetas até acabar vivendo no interior de uma baleia gigante) é uma evidente mentira. Porém, aí reside a virtude de suas narrativas: "me voltei para a mentira, em muito mais honesta que a dos demais, pois ao menos nisto direi a verdade: ao afirmar que minto".

\section{Luciano filósofo?}

Ainda que identifiquemos neste proêmio certa posição filosófica de Luciano é preciso lembrar do que afirma Jacyntho Lins Brandão para quem o autor "pósantigo" não se tratava de um filósofo, aliás, nem se pretendia um, do mesmo modo que não se tratava de um historiador. Ao reconhecer a distância entre seus escritos e daqueles é que podia tomar suficiente distância para tecer suas críticas. Assim, ainda que se possam verificar abordagens que insistem em qualificar o escritor como um filósofo da época da Segunda Sofística, Brandão explicita como todas as características desta Segunda Sofistica, e demais doutrinas filosóficas em disputa então, são objeto de ácida crítica de Luciano: "Todos os que filosofam, como diz o ditado, combatem pela sombra do asno"6.

Estudiosos do corpus luciânico mostram que este tomado como um todo deixa isso mais claro, como em Hermotimo ou As Escolas Filosóficas, ali:

[...] Luciano não poupa ninguém. No entanto, é justo salientar que, mais que as doutrinas filosóficas, ele verberava sobretudo os seus representantes atuais, cheios de orgulho e de certezas absolutas. Mesmo assim, pelo seu racionalismo ou pelo desprezo pelas convenções sociais, Luciano admira principalmente os epicuristas e os cínicos (MAGUEIJO, 2012, p. 1667).

\footnotetext{
${ }^{5}$ É possível encontrar duas viagens à Lua nas obras de Luciano de Samósata, além do relato da guerra entre habitantes do Sol e da Lua em Narrativas Verdadeiras, em Icaromenipo o autor sírio descreve o relato da viagem de Menipo, que, equipado de uma asa de abutre e uma de águia, sobe aos céus em busca de conhecimento, chegando a Lua encontra seu solitário habitante: Empédocles, filósofo que ao tentar o suicídio se atira nas águas do Etna e, segundo a versão luciânica, é arrebatado e lançado até a Lua onde vive alimentando-se de orvalho. Além de Empédocles o próprio Menipo trata-se de figura histórica (autor grego tido como o criador da sátira menepéia) e, segundo Jacyntho Brandão, personagem com o qual Samósata "situa a tradição das viagens aéreas no campo (pelo menos satírico) das preocupações filosóficas". Neste texto a própria Lua toma a palavra pedindo a Zeus que interceda contra os filósofos, os quais não lhe deixam em paz, envolvendo-a em discussões sobre sua real natureza (BRANDÃO, 2007).

${ }^{6}$ Apud BRANDÃO, 2001, P.54.
} 
Porém, mesmo entre os cínicos ou entre os epicuristas, afirma o tradutor português, Luciano encontra indivíduos desprezíveis, precisamente pelo fato de não viverem como dizem pensar. Se, não se pode alinhar indiscriminadamente Luciano a qualquer escola filosófica de então, o rótulo de exemplar da Segunda Sofística tão pouco será preciso.

\section{Segunda Sofística}

O termo "Segunda Sofística" foi originalmente cunhado por Flávio Filóstrato (170-250) sofista que, na obra Vidas dos Sofistas (na qual não se encontra referência a Luciano), classifica como "primeira" sofística a praticada em Atenas no século V a. C. por figuras como Górgias e Protágoras e, apesar de identificar o movimento de que faz parte com esta, não o faz a ponto de considerá-lo sua continuação. A primeira se trataria da sofística praticada na Ática clássica preocupada com a retórica filosófica, enquanto a segunda designa o período entre os séculos I e III d.C., e estaria mais preocupada com a retórica enquanto tal. Essa visão vaga e tendenciosa de Filóstrato, no entanto, dá lugar atualmente a uma visão mais afastada e imparcial que não vê uma ruptura entre a Primeira e a Segunda Sofística, mas sim um movimento de continuidade que opera a memória helênica no seio da Roma Imperial. ${ }^{7}$

Para Goldhill ${ }^{8}$ a cultura grega é, em autores romanos helenizados como Filóstrato e Luciano, parte fundamental dos seus projetos intelectuais e sociais, mas o modo como cada um a representa é muito diverso. Durante o Império a identidade grega não é definida pela genealogia ou pelo local de nascença, mas pelos hábitos, pela língua, pelas referências e pela aparência; a identidade grega é um estilo socialmente construído, a adequação a conceitos valorizados em conjunto (dicção, aparência, inteligência, civilidade, masculinidade).

Só podemos aproximar Luciano da Segunda Sofística com facilidade por essa segunda concepção mais ampla, pois se tratarmos do conceito como originalmente apresentado por Filóstrato fica mais difícil: a preocupação de Luciano com a retórica é idiossincrática e mesmo o modo como Luciano faz alusão ao classicismo grego com sua comicidade crítica lhe deixa numa posição muito particular.

Jacyntho Lins Brandão adverte para o fato de que a princípio Luciano é "orador e sofista", porém, "ultrapassa os limites da retórica de aparato" vista em demais representantes ilustres da Segunda Sofística abordada por Filóstrato. Esse pode ser, segundo o estudioso brasileiro, um dos motivos de Luciano não figurar entre os

\footnotetext{
7 MARTINS, Paulo; BRENER, Pedro Zanetta, Novas luzes sobre a Segunda Sofística, CODEX - Revista de Estudos Clássicos, v. 5, n. 2, p. 11, 2017.

8 GOLDHILL, Simon, Being Greek under Rome: Cultural Identity, the Second Sophistic and the Development of Empire, New York: Cambridge University Press, 2001.
} 
sofistas nas Vidas dos Sofistas. A crítica de Luciano ao discurso sofista, no entanto, não nos permite colocá-lo de outro lado como um filósofo que propõe como alternativa a sofistica um sistema filosófico: como vimos todos também são objeto de sua crítica9.

\section{Uma reflexão luciânica}

Mais que procurar a reflexão de um filósofo antigo no proêmio Das Narrativas Verdadeiras se pode vislumbrar a abordagem de um literato sobre os filósofos e suas práticas. Em certa medida, mais que tratar da relação entre filosofia e literatura se pode, a partir de Luciano, pensar certa vantagem crítica da literatura frente à filosofia: o distanciamento gerado pelo discurso ficcional oferece uma posição privilegiada para a o discurso crítico. Mais que descrever uma viagem fantástica as Narrativas luciânicas se caracterizam por descrever as características físicas e comportamentais dos habitantes do espaço e da baleia, sobretudo no intuito de comparar e satirizar características e comportamentos humanos; traços dos escritos de Luciano que ficaram conhecidos: a ironia e a sátira.

Em Das Narrativas Verdadeiras (uma paródia da Odisseia) a Lua é descrita como um lugar amplamente habitado. Nela Luciano o personagem e narrador, em uma jornada - motivada pela busca de conhecimento - para além do estreito de Gibraltar (as colunas de Hércules) onde o navio, após conhecer ilhas ao modo Odisseu, acaba por ser elevado aos céus por um tufão, e, após sete dias e sete noites, aporta na Lua. Ainda que essa viagem em busca de conhecimento e de um distanciamento da Terra para fazer a crítica da sociedade humana, possa ser vislumbrada em historiadores e filósofos anteriores a Luciano, o autor sírio como vimos, alerta seus leitores de que tudo não passa de uma mentira. Assim, se se pode dizer que o autor conta mentiras, ao contrário de seus predecessores, trata-se de uma mentira desculpável, na medida em que o autor admite se tratar de uma ficção. Conforme Jacyntho Brandão esses são três aspectos que mais se destacam nesta narrativa: "a intenção epistemológica, a confissão de ficcionalidade e o relato em primeira pessoa que apaga intencionalmente a fronteira entre autor e narrador" ${ }^{\circ}$.

A intenção epistemológica - essa motivação pelo saber que moverá boa parte dos personagens dos representantes vindouros da tradição luciânica - se deixa ver no ímpeto de descrever além dos limites do mundo conhecido. Mas, é a confissão de ficcionalidade o que torna paradigmática a posição de Luciano assumida no proêmio. Ao assumir que mente, e, portanto, elabora uma ficção, evidencia que essa teria sido a prática de muitos antigos poetas, historiadores e filósofos que ajudavam

\footnotetext{
9 Cf.BRANDÃO, A poética do hipocentauro: literatura, sociedade e discurso ficcional em Luciano de Samósata. Belo Horizonte, 2001, pp.65-76.

${ }^{10}$ BRANDÃO, 2007.
} 
a forjar a cultura, ou seja, a "história real". O relato em primeira pessoa ajuda a confundir o limite entre realidade e ficção, mas é sua descrição da Lua como essa outra Terra que permite um espelhamento crítico em que a ficção já não serve mais ao puro deleite do leitor, e sim como ferramenta crítica da realidade.

Assim, parece mais que apropriado o genitivo na tradução do título como Das Narrativas Verdadeiras: além de uma narrativa fabulosa esse texto se propõe um questionamento sobre as narrativas que se afirmam verdadeiras. Uma espécie de narrativa que por meio da sátira e da ironia oferece uma ferramenta crítica para se avaliar e avaliar demais narrativas.

Ao descrever de forma verossímil os detalhes de sua viagem esse embaralhar crítico entre ficção e realidade faz rir e pensar: Luciano procura focar sua etnografia nas características bizarras dos seres por ele apresentados como forma de evidenciar o caráter bizarro da narrativa e da própria humanidade.

\section{Etnografia lunar}

Se em Icaromenipo Luciano já havia descrito a viagem de um personagem histórico até a lua é em Das Narrativas Verdadeiras que o satélite é descrito, pelo autor narrador, como um lugar amplamente habitado e a narrativa de viagem ganha um aspecto propriamente etnográfico ${ }^{11}$.

Dos muitos aspectos da etnografia lunar luciânica Jacyntho Lins Brandão chama atenção para alguns: “a) sexo e procriação; b) natureza animal, vegetal e produção de utensílios; c) alimentação e dejetos; d) diversidades natural, econômica e cultural"12. Luciano com essas descrições faz com que haja um apagamento da fronteira seja entre vegetais e animais, como entre natural e artificial; gera uma reflexão nova a partir da radicalização de ideias presentes em filósofos e historiadores que lhe precederam e abre caminho para a crítica de costumes.

Os selenitas aí descritos são seres muito diversos dos que habitam a Terra: não são gerados por fêmeas, mas por machos que não os concebem pelo ventre, mas pela barriga da perna (motivo pelo qual o autor atribui essa definição para a panturrilha), outra espécie (dendritas) nascem como frutos de plantas em forma de pênis (que brotam quando se enterra o testículo de um deles). Os habitantes lunares descritos por Luciano usam órgãos sexuais postiços: os ricos de marfim e os pobres de madeira; se alimentam do odor exalado quando assam rãs voadoras; suas vestes são de cristal macio (os ricos) ou de cobre com o qual se faz uma lã (os pobres); não possuem sistema excretor, e, entre outras características, seus olhos podem ser retirados e colocados; quando envelhecem não morrem, mas viram fumaça.

\footnotetext{
${ }^{11}$ Ainda que haja também a descrição de outros habitantes celestes como os Heliotas (habitantes do Sol) para nossa abordagem aqui nos limitaremos a descrição dos Selenitas (habitantes da Lua).

${ }^{12}$ BRANDÃO, Cyrano de Bergerac e a tradição luciânica.
} 
Muitas das fontes dessas "características bizarras" das descrições de Luciano estão na mitologia e nos antigos poetas, mas boa parte de suas alusões são a historiadores e filósofos. Além de estas alusões mostrarem um modo nada servil de Luciano resgatar a cultura helênica, compõem os personagens da sátira de costumes que marcarão seu legado.

\section{A tradição luciânica}

Luciano constrói sua narrativa deliberadamente por meio da alusão e escolhe a viagem como ocasião para narrar o encontro com o fabuloso, com a ficção, com uma mentira em alguns aspectos verossímil: ao mesmo tempo uma alusão à poesia épica, quando Odisseu descreve suas aventuras aos Feácios, e aos relatos dos historiadores, que se pretendiam descrições fiéis da realidade.

Além dessa herança de Das Narrativas Verdadeiras a tradição luciânica se caracteriza também por outras particularidades presentes no corpus luciânico que (para além da vinculação à Segunda Sofística) é também considerado como uma variação da chamada tradição menepéia.

Menipo, outro autor sírio helenizado que viveu no século III a.C. nascido em Gadara, o qual foi personagem em textos de Luciano e, apesar de nada de sua obra ter chego até nós, é conhecido por criar o gênero literário que ganhou seu nome.

A sátira menepéia ficou conhecida como um tipo de paródia que desrespeitaria as tradições literárias vigentes. A partir do escritor romano Marco Terêncio Varrão (116-27 a.C.) passou-se a diferenciá-la da sátira romana: esta última estaria marcada pelo aspecto formal por ser constituída de versos hexâmetros (o padrão do metro épico tanto dos gregos como dos romanos) e do ponto de vista moral cumpriria a função social de, por meio do riso, denunciar os vícios da sociedade e, assim, tornála melhor; já a sátira menepéia, não obedece modelo formal misturando mesmo versos com prosa e, do ponto de vista moral, não assume nenhum compromisso além de, através do riso, falar com seriedade ${ }^{13}$.

Luciano de Samósata, nessa medida, seria um representante dessa tradição menepéia e um de seus mais importantes divulgadores, por outro lado não podemos dizer que se trata de um simples continuador de uma longa tradição literária sem ignorar sua evidente inovação. Para ilustrar essa originalidade vejamos o que escreve Enylton José de Sá Rego o qual afirma que "as principais características da obra de Luciano podem ser resumidas em cinco pontos":

1) criação - ou continuação - de um gênero literário inovador, através da união de dois gêneros até então distintos: o diálogo filosófico e a comédia; 2) utilização sistemática da paródia aos

\footnotetext{
${ }^{13}$ Cf.REGO, 1989, (pp. 31-36).
} 
textos literários clássicos e contemporâneos, como meio de renovação artística; 3) extrema liberdade de imaginação, não se limitando às exigências da história ou da verossimilhança; 4) estatuto ambíguo e caráter não moralizante da maior parte de sua sátira, na qual nem o elemento sério nem o elemento cômico tem preponderância, mas apenas coexistem; 5) aproveitamento sistemático do ponto de vista do kataskopos, ou observador distanciado, que, como um espectador desapaixonado, analisa não só o mundo que se refere como também a sua própria obra literária, a sua própria visão de mundo (REGO, 1989, p.45-46).

De modo geral podemos dizer que essas características são o que constituem o cerne da chamada tradição luciânica. Essa tradição literária, inaugurada por Luciano de Samósata, que encontra seus ecos em textos das mais diversas épocas. Foi na Renascença, contudo, que seu resgate lhe apresentou ao mundo moderno e fez com que, ainda que de modo discreto, chegasse até nós.

Das Narrativas Verdadeiras inaugura ainda outra tradição literária: a das narrativas de viagens espaciais, em especial das viagens à Lua. É preciso lembrar que se podemos atribuir certa paternidade de gênero literário a Luciano de Samósata, não se ignora a originalidade que essa tradição luciânica ganha com cada uma de suas novas expressões, seja antes do libertino setecentista Cyrano de Bergerac (Viagem à Lua - 1657), seja depois dele com Edgar Alan Poe (As aventuras sem par de um certo Hans Pfall - 1835), Júlio Verne (Da Terra à Lua -1865) e H. G. Wells (Os primeiros homens na Lua - 1901); sem contar nas expressões cinematográficas e audiovisuais desde Georges Méliès e sua Viagem à Lua (1902) até as renovadas produções sobre viagens interplanetárias.

Mais que um exame detido de cada uma das expressões dessa tradição luciânica (que, mais que o relato de viagem, se caracteriza pela intersecção entre ficção e facticidade, não sem carregar-se de exagero, ironia, sarcasmo e sátira - em uma palavra humor), busca-se aqui, ainda que de modo modesto, a partir da análise do proêmio das Narrativas e do contexto geral da obra, refletir sobre as consequências dessa tradição literária para o pensamento filosófico e a produção literária moderna.

\section{Ecos de Luciano na modernidade}

Se Luciano foi, de certa forma, eclipsado na idade média, a modernidade encontrou em sua obra as referências para uma criação intelectual que procurava se renovar. Obra de um pagão entre os cristãos, seus textos passam figurar nas bibliotecas do século XVI muito devido a Erasmo de Roterdã (1466-1536); não só por se inspirar em Luciano para compor seu Elogio da Loucura (1509), mas por ter (em 
conjunto com Thomas Morus) publicado uma série de traduções de textos de Luciano $^{14}$.

Um bom exemplo do eco da obra de Luciano, em especial das Narrativas, é Johannes Kepler e seu Somnium [Sonho] 15 (1634) (editado postumamente), no qual admitiu que se inspirou em "uma tradição de narrativas ficcionais com teor filosófico: o Sonho de Cipião, de Cícero, a História verdadeira, de Luciano, e, principalmente, o Sobre a face que aparece no orbe da Lua (De facie quae in orbe lunae apparet), de Plutarco" ${ }^{16}$.

O papel de Luciano no debate [da assim chamada filosofia natural e] da ciência moderna nascente se torna explicito quando uma mente como a de Kepler ao inserir-se na "tradição das narrativas oníricas e nos relatos de viagem a ilhas distantes" ${ }^{17}$ faz no Somnium, na nota 2, não só referência ao autor sírio como evidencia sua importância na compreensão não apenas do grego, mas do carácter funcional da ficção presente no proêmio analisado:

Nota 2: "Mais tarde me deparei com os dois livros de Luciano, História verdadeira, escrita em grego. Eu escolhi estes opúsculos para aprender a língua além de desfrutar dessa fábula audaciosa, que, porém, aponta algo da natureza de todo o universo, como Luciano lembra em sua introdução" (KEPLER, J. Sonho. Apud BRANDÃO, 2020, pp. 104, nota 08).

Essa possibilidade oferecida pela ficção dos antigos se apresenta, conforme Rodrigo Brandão, como "caução ao uso da ficção para tratar do conhecimento filosófico" ${ }^{18}$. Além da autoridade da literatura antiga, a ficção é o que possibilita com que todos os fenômenos celestiais sejam relativizados e aprendamos sobre nós ao adotar o ponto de vista permitido pela viagem:

Ora, para Kepler, como mostrou a nota 2, mesmo a História verdadeira, de Luciano, serve para conhecer a natureza das coisas. De maneira geral, a ficção lhe serve para avançar observações de fenômenos e corpos celestes, ou como diz em outra ocasião: "Volto aqui a contemplar a natureza dos corpos utilizando a ficção" (BRANDÃO, 2020, p. 104-105).

Durante o século XVII teremos uma série de outros autores que podem ser filiados a esta tradição luciânica. Cyrano de Bergerac (1619-1655) se insere aí como

\footnotetext{
${ }^{14}$ Cf.Ibid.(pp.69-76).

${ }^{15}$ RIBEIRO, Jair Lúcio Prados, O Sonho de Johannes Kepler: Uma tradução do primeiro texto de hard sci-fi, Revista Brasileira de Ensino de Fisica, v. 40, n. 1, p. e1602, 2018.

${ }^{16}$ BRANDÃO, Rodrigo, Filosofia e Imaginação no Sonho, De Kepler, e nos Diálogos Sobre a Pluralidade dos Mundos, de Fontenelle, Cadernos Espinosanos, v. jan-jun, n. 42, p. 99-123, 2020.

${ }^{17}$ Ibid.pp. 103-104.

${ }^{18}$ Ibid.p.104.
} 
uma das mais famosas dessas filiações com sua Viagem à Lua. Nela, além da viagem pressuposta no título, há a novidade da primeira máquina imaginada para viagens espaciais: a qual por conta da atração da Lua e da posição geográfica teriam lhe elevado ao espaço.

Anos depois em 1638 aparece The Man in the Moon (O homem na Lua), de autoria do prelado anglicano Francis Godwin, no qual a viagem é mediada por uma máquina que chega à Lua puxada por gansos (confirmando a antiga crença de que é pra lá que migram esses pássaros no outono). Essas três obras seiscentistas além de conterem uma inspiração luciânica acabam por reproduzir o dispositivo da paródia e da alusão entre si: podemos encontrar em Cyrano referências diretas à Kepler bem como um encontro lunar com o personagem da viagem de Godwin.

É por isso que se pode falar propriamente de tradição, vale dizer, uma ambientação em que a verve luciânica se desdobra em diferentes funções, a mais surpreendente delas, sem dúvida, o tornar palatáveis as novidades científicas dos primeiros séculos da era moderna (BRANDÃO, 2007).

Ou como afirma Rodrigo Brandão: trata-se de um resgate de Luciano e demais autores antigos "dentro de um quadro da astronomia moderna" (2020, p. 105).

Um ponto importante para diferenciar Luciano de seus "êmulos" do século XVII, como afirma Jacyntho Lins Brandão, é que aquele se tratava de um autor antigo e pagão e as dissonâncias entre suas Narrativas e a teologia cristã ficam a cargo de seus leitores, já estes setecentistas, além de utilizar sua ficção para "tornar palatáveis as novidades científicas" modernas, precisam lidar com essa dissonância de modo mais cuidadoso: um dos prováveis motivos para que as três ficções modernas tenham sido publicadas apenas após a morte de seus autores. No caso de Cyrano esse aspecto é acrescido de mais dois fatos: o amigo e editor Henri Le Bret mudou o título - que originalmente constava como $O$ outro mundo ou os Estados e Impérios da Lua - para História cômica; não bastando isso, censurou parte do texto que julgou ofender as bases da religião e do Estado para proteger o editor, ou seja, o próprio Le Bret.

A partir dessa tradição de relatos de viagens espaciais - que revela a ancestralidade das ficções científicas - vemos como a ficção literária retroalimenta as especulações filosóficas e vice versa; e, mais precisamente, como a tradição literária inaugurada por Luciano se tornou um aparato crítico e criativo mais presente na cultura letrada ocidental do que s uas referências marginais podem sugerir. Ou seja, chamamos atenção aqui para uma tradição, que continuará nos séculos seguintes até os dias de hoje, importante não só para a história da literatura, como da filosofia e da ciência. 
Se os selenitas de Luciano foram extintos de nosso imaginário desde a Apolo IX em 1969, os extraterrestres só foram exilados para lugares mais longínquos, os quais ainda não foram totalmente desvelados pela ciência e restam como objeto da ficção de literatos e da especulação dos filósofos, ou ainda, levando em conta a tradição luciânica, nas obras que conjugam ficção e especulação filosófica.

Para além do aspecto científico que se incorpora a essa tradição luciânica na modernidade, não se deixará de ver a sátira e a crítica de costumes possibilitada pelo distanciamento provocado pela narrativa de viagens e o embaralhar entre ficção e realidade.

É possível encontrar referências à tradição luciânica desde o final do Império Romano até os textos de Machado de Assis, mais que com referência direta as reflexões provocadas por essa tradição literária pode se fazer notar nos mais diversos contextos. As reflexões dos filósofos brasileiros da Escola do Recife, no final do século XIX, sobre as vantagens críticas da literatura frente à filosofia parecem reverberar muito dessa reflexão luciânica, por exemplo, ao afirmarem que os filósofos só podem investigar a alma humana por meio da introspecção, o que faz do procedimento filosófico algo pouco objetivo. Já os literatos, ao transporem a alma humana para um personagem, ganham o distanciamento crítico que em relação aos filósofos, falta.

Ainda hoje, para além das ficções científicas, os ecos da tradição luciânica, e todas as suas características, continuam provocando nossa reflexão sobre a literatura e sua função/compromisso com a produção de conhecimento. E, no seio da História da Filosofia, a tradição literária inaugurada por Luciano tem se feito presente, não apenas como uma referência, mas como uma ferramenta crítica - com artifícios como o afastamento e o humor - capaz de oferecer novos pontos de vista tanto para a crítica dos costumes como para as elaborações sobre o papel da imaginação no desenvolvimento dos conhecimentos científicos e filosóficos.

\section{Referências}

BRANDÃO, J. L. A poética do hipocentauro: literatura, sociedade e discurso ficcional em Luciano de Samósata. Belo Horizonte: Ed. UFMG, 2001.

. “Cyrano de Bergerac e a tradição luciânica”. In: MORETTO, Fulvia M. L.

(Org.). Viagem à lua. São Paulo: Globo, 2007.

BRANDÃO, R. "Filosofia e Imaginação no Sonho, De Kepler, e nos Diálogos Sobre a Pluralidade dos Mundos, de Fontenelle”. In: Cadernos Espinosanos, v. jan-jun, n. 42, p. 99-123, 2020.

GOLDHILL, S. Being Greek under Rome: Cultural Identity, the Second Sophistic and the Development of Empire. New York: Cambridge University Press, 2001. 
MARTINS, P; BRENER, P. Z. "Novas luzes sobre a segunda sofística”. In: CODEX Revista de Estudos Clássicos, v. 5, n. 2, p. 11, 2017.

REGO, E. S O calundo e a panacéia: Machado de Assis a sátira menipéia e a tradição luciânica. Rio de Janeiro: Forense Universitária, 1989.

RIBEIRO, J. L P. "O sonho de Johannes Kepler: uma tradução do primeiro texto de hard sci-fi". In: Revista Brasileira de Ensino de Fisica, v. 40, n. 1, p. e1602, 2018.

SAMÓSATA, L. Obras completas. Coimbra: Imprensa da Universidade de Coimbra, 2012.

SANO, L. Das narrativas verdadeiras, de Luciano de Samósata: Tradução, Notas e Estudo. USP, 2008.

Submissão: 01. 06. 2021 / Aceite: 25. 10. 2021 